approach may have avoided chronicity with the return of patients to the care of their GP.

Our study identified difficulties and omissions in data recording. This has been radically modified as the result, particularly in recording dates of attendance, default rates, first contact to service, specific interventions, prescribing practice, and rating scales. It has been essential to make these improvements to our database in advance of any expansion of the service to take referrals directly from GPs or to manage a small in-patient unit. We propose further studies looking at those patients re-referred to Panmure House, as well as the subsequent functioning and use of mental health services by a random group of those patients discharged from this new service.

\section{References}

GoldBerg. D. P. \& WILlaA. P. (1988) A Users Guide To The General Health Questionnaire. Windsor: NFER Nelson.

MARKS, I. M., CoNnOlly, J., MUiJYen, M., et al (1994) Homebased versus hospital-based care for people with serious mental illness. British Journal of Psychiatry. 165. $179-194$
TYRER, P. (1990) Personality disorder and social functions. In Measuring Human Problems: A Practical Guide (eds D. F. Peck \& C. M. Shapiro), pp. 119-142. Chichester: John Wiley.

WORLD HEALTH ORganization (1978) Mental Disorders: Glossary and Guide to their Classification in Accordance with the Ninth Revision of the International Classification of Diseases (ICD-9). Geneva: WHO.

- (1992) The Tenth Revision of the International Classification of Diseases and Related Health Problems (ICD-10). Geneva: WHO.

Zigmond, A. S. \& SNATTH, R. P. (1983) The Hospital Anxiety and Depression Scale. Acta Psychiatrica Scandinavica. 67. 361-370.

S. J. Brown, Registrar in Psychiatry. Greater Glasgow Community and Mental Health Services NHS Trust, Gartnavel Royal Hospital, Glasgow; M. F. Guthrie, Senior Registrar, Department of Psychiatry. University of Dundee, Dundee; and *B. M. Shepherd, Consultant Psychiatrist, Dundee Healthcare NHS Trust, Royal Dundee Liff Hospital, Dundee DD2 5NF

*Correspondence

\title{
Psychiatric morbidity in patients referred for individual psychotherapy within and outwith the NHS
}

\author{
John R. Mitchell and Chris P. Freeman
}

\begin{abstract}
Aims and melthod Demographic and medical characteristics of waiting list patients for National Health Service (NHS) psychotherapy, non-NHS psychotherapy or NHS general adult psychiatry were compared by postal questionnaires.

Results One hundred and eighty-three subjects replied. High rates of psychiatric morbidity were reported in both psychotherapy populations but general psychiatric referrals were more disturbed, taking more psychotropic medication than non-NHS psychotherapy but not NHS psychotherapy subjects. The biggest referral source to non-NHS psychotherapy was general practitioners.
\end{abstract}

Clinical implications Non-NHS psychotherapists should be able to recognise severe mental illness and have a basic understanding of psychotropic medication and psychiatric services.

Controversy exists as to whether psychotherapy is an effective treatment for psychiatric disorder (Andrews, 1993; Holmes \& Marks, 1994) and whether psychotherapy patients are the worried well' (Amies, 1996). Despite a joint statement by the British Psychological Society and Royal College of Psychiatrists (1993), psychiatrists are 
divided in their opinions of psychotherapy (Hinshelwood, 1994). The general public perceives 'counselling' as the answer to all problems resulting from personal unhappiness (Furnham \& Wardley, 1990). No single, UK body regulates non-National Health Service (NHS) psychotherapists although the establishment of the United Kingdom Council for Psychotherapy (UKCP) in 1993 and the British Confederation of Psychotherapists (BCP) in 1995 is progress. Current Government policy targets NHS resources at the seriously mentally ill. Less resource for the 'neurotic' or 'worried well' makes general practitioners (GPs) and individuals look beyond traditional psychiatric services for counselling. Little is known about non-NHS psychotherapy service users. Levels of psychiatric morbidity, proportions that would be assessed as suitable for NHS psychotherapy and reasons for individual preference of treatment models are uncertain (Tasca et al, 1994). This study looks at levels of psychiatric morbidity, referral and demographic details in waiting list subjects for non-NHS psychotherapy and compares these with waiting list NHS psychotherapy and NHS general adult psychiatry subjects.

\section{The study}

Subjects were from three sources: NHS individual psychotherapy patients $(n=23)$ on the waiting list for psychodynamic psychotherapy at the Royal Edinburgh Hospital Department of Psychotherapy; non-NHS individual psychotherapy patients $(n=99)$ on the waiting list for individual psychotherapy/counselling at the "Number 21 Counselling Service", a voluntary organisation in the centre of Edinburgh; and NHS general psychiatric out-patients ( $n=61$ ) on the waiting list for general adult psychiatric out-patient assessment and treatment, referred by south-west Edinburgh GPs.

Subjects were sent a study explanation, an anonymous questionnaire asking personal details, and the Symptom-Check List SCL-90-R, a 90-item self report symptom inventory developed by Derogatis (1983), which reflects psychological symptom patterns.

\section{Findings}

Response for the groups' rates were NHS psychotherapy, $74 \%$, non-NHS psychotherapy, $52 \%$, and NHS general psychiatry, $41 \%$. The majority of subjects awaiting psychotherapy were women, $70 \%$ of the NHS group and $77 \%$ of the non-NHS group compared with $56 \%$ of the NHS general psychiatry group (Pearson $\chi^{2}$ analysis $P=0.02$ ). Analysis of variance showed no significant difference between the age of subjects, but the majority of non-NHS psychotherapy subjects were around 30 years old.

NHS psychotherapy subjects and non-NHS psychotherapy subjects lived across Edinburgh with no postcode differences representing socioeconomic class extremes. Non-NHS psychotherapy patients had significantly longer education since the age of five years than general psychiatry patients $(P=0.048)$.

Thirty-one per cent of non-NHS psychotherapy subjects were on psychotropic medication with $24 \%$ taking antidepressants. This was significantly less $(P=0.006)$ than the $48 \%$ of NHS psychotherapy subjects and 57\% of NHS general psychiatry subjects taking psychotropic medication. Non-NHS psychotherapy subjects took more non-psychotropic medication $(22 \%)$ than NHS psychotherapy subjects $(9 \%)$ and NHS general psychiatry subjects $(8 \%)(P=0.041)$.

Eleven per cent of non-NHS psychotherapy and $40 \%$ of NHS psychotherapy subjects were attending a psychiatrist $(P<0.001)$. There was no significant difference between the past contact of either psychotherapy group subjects with general psychiatry, NHS or non-NHS psychotherapy, and no significant differences in attitudes to past experience of psychotherapy whether NHS or non-NHS.

Thirty-three per cent of referrals to non-NHS psychotherapy were self-referrals, $48 \%$ came from GPs and $2 \%$ from psychiatrists, other sources included social workers, support workers and friends. GPs also had made the most referrals to NHS psychiatry (52\%).

SCL-90- $R$ responses were converted into gender adjusted ' $T$ ' scores. Higher $T$ scores indicate greater symptom severity. Analysis of variance was performed using $F$ ratios. $T$-tests were used to compare means as shown in Table 1.

NHS and non-NHS psychotherapy subjects had little difference in symptom severity. General psychiatry subjects had significantly higher levels of depression and anxiety compared to non-NHS psychotherapy subjects as reflected by higher use of antidepressants and anxiolytics. Somatisation scores were lowest in non-NHS psychotherapy subjects although this group reported the highest use of non-psychotropic prescribed medication. This suggests that nonNHS psychotherapy subjects either have higher levels of physical illness but do not complain about it as much or they were more precise in recording all the medicines they were on compared to NHS psychotherapy and NHS psychiatry patients.

The Global Severity Index of the SCL-90-R represents the best summary indicator of the current depth of an individual's distress. General psychiatry subjects were significantly more distressed than non-NHS psychotherapy subjects. Caseness analysis indicates that NHS 
Table 1. Symptom Check-List (SCL-90-R) dimension and index means

\begin{tabular}{llll}
\hline Dimension & $\begin{array}{l}\text { Group } 1 \text { NHS psychotherapy } \\
(n=21)\end{array}$ & $\begin{array}{l}\text { Non-NHS psychotherapy } \\
(\boldsymbol{n}=97)\end{array}$ & $\begin{array}{l}\text { NHS general psychiatry } \\
(\boldsymbol{n}=58)\end{array}$ \\
\hline Somatisation & 50.86 & 49.92 & $54.71 P=0.022^{*}$ \\
Obsessive-compulsive & 53.62 & 50.95 & 51.24 \\
Interpersonal sensitivity & 55.95 & 51.76 & 52.24 \\
Depression & 54.19 & 51.99 & $55.03 P=0.035^{*}$ \\
Anxiety & 49.24 & 48.59 & $52.16 P=0.012^{*}$ \\
Hostility & 54.10 & 50.52 & 50.12 \\
Phobic anxiety & 45.29 & 41.59 & 47.60 \\
Paranoid ideation & 55.52 & $49.45 P=0.04^{*}$ & 50.31 \\
Psychoticism & 48.10 & 47.42 & 48.32 \\
Global Severity Index & 53.32 & 50.46 & $54.16 P=0.014^{*}$ \\
Positive Symptom Total & 56.33 & 53.26 & 53.76 \\
Positive Symptom Distress index & 48.48 & 48.53 & $51.69 P=0.025^{*}$ \\
Caseness (\% subjects) & 47.6 & 22.7 & $37.9 \chi^{2} P=0.028^{*}$ \\
\hline
\end{tabular}

${ }^{*} P<0.05$

psychotherapy subjects were the most distressed and non-NHS subjects the least.

\section{Comment}

Differing response rates and group sizes limit results. however it is helpful that the largest group of subjects belonged to the group of primary interest, the non-NHS psychotherapy service users.

Non-NHS individual psychotherapy service users tended to be women, in their $30 \mathrm{~s}$ and better educated than general psychiatry patients. The gender difference was similar in previous studies (Doidge et al, 1994; Evans et al, 1995). These were not the 'worried well' around a third were on psychotropic medications, over a tenth were attending a psychiatrist and over a fifth fulfilled caseness criteria. They were, however, less psychiatrically disturbed than their NHS psychotherapy counterparts who were less disturbed than general psychiatry out-patients. This is reassuring. However, a tenth of the individuals awaiting non-NHS psychotherapy and fulfilling caseness criteria had no ongoing psychiatric contact, including two subjects on antipsychotic medication.

No significant differences existed between NHS and non-NHS psychotherapy subjects past contact with psychiatry/psychotherapy or their attitudes to this. Handwritten comments requested more NHS counselling provision. Over half (59\%) of non-NHS subjects had past experience of NHS mental health services, either psychiatric or psychotherapeutic. Only $37 \%$ were coming to non-NHS psychotherapy with no past experience of NHS or non-NHS mental health services. Sixteen per cent of non-NHS subjects with attitudes to past NHS psychotherapy were positive and an equal number were negative. The same was found of non-NHS treatment. Subjects going to non-NHS services had not necessarily a bad past experience of NHS care.

GPs had made the majority of referrals to the Number 21 Counselling centre with Edinburgh wide distribution. The 1994 annual report of the Number 21 Counselling centre records $26 \%$ of referrals from GPs and none from psychiatrists. GP referral increase may reflect recent mental health care changes in Edinburgh. GP purchasers may be less keen to buy psychotherapy from the NHS when it is free from the voluntary agencies who had shorter waiting lists. However, the increase in outpatient general psychiatric referrals by $163 \%$ between 1989 and 1995 would make it necessary to look at referrals specifically to NHS psychotherapy and community psychiatric nurses. The general public are more informed about health care rights with the notion of 'counselling' as the panacea of all ills (Wong, 1994). GPs may be referring secondary to more patient demand.

Margison \& Stewart (1996) looked at GP and specialist referrals to a NHS psychotherapy centre. They found agreement on the level of service and the indications for its use. GPs seemed well informed. Other studies have focused on GP referrals to NHS psychotherapy (Morton \& Staines, 1993; Maloney, 1993), but this study looks at referrals to a non-NHS service. GPs may not know what they want when they refer a patient. Undergraduate psychiatry teaching includes little on psychotherapy and doctors often remain confused as to what it is and what it is for. In a recent unpublished survey of 60 Edinburgh GPs (further details avallable from the author upon request), under a half had senior house officer psychiatry experience.

Current public demand for 'counselling' with the limited resources of NHS psychiatry means other sources of psychotherapy are used. NHS psychiatrists ought to identify ways in which services can 
more effectively coexist. To protect vulnerable individuals who may be treated with psychotherapy outwith the NHS appropriate standards of ethics, practice and training are essential for nonNHS psychotherapists. These psychotherapists should be able to recognise severe mental illness and have a basic understanding of psychotropic medication and psychiatric services.

\section{Acknowledgements}

We thank the service users and staff of the Number 21 Counselling Centre, Edinburgh as well as the patients of the Royal Edinburgh Hospital who agreed to be involved.

\section{References}

Amies, P. (1996) Psychotherapy patients: are they the worried well'? Psychiatric Bulletin. 20. 153-156.

ANDREWS, G. (1993) The essential psychotherapies. British Journal Psychiatry. 162, 447-451.

DEROGATIS, L. R. (1983) SCL-90-R: Administration, Scoring and Procedures. Towson. MD: Clinical Psychometric Research. Inc.

Doidge, N., Simon, B., Gilues, L. A., et al (1994) Characteristics of psychoanalytic patients under a nationalised health plan: DSM-III-R diagnosis. previous treatment, and childhood trauma. American Joumal of Psychiatry. 161, 586-590.

EVANS, J., HARTMAN, J. \& GladWELL, S. (1995) Diagnostic survey in a regional psychotherapy unit. Psychiatric Bulletin. 19, 673-675.
FurnhaM, A. \& WARDLEY, Z. (1990) Lay theories of psychotherapy 1: Attitudes towards, and beliefs about. psychotherapy and therapists. Joumal of Clinical Psychology, 46. 878-890.

HINSHELWOOD, R. D. (1994) The relevance of psychotherapy. Psychoanalytic Psychotherapy. 8. 283-294.

Holmes, J. \& MARKS, l. (1994) Psychotherapy - a luxury the NHS cannot afford? British Medical Journal. 809. 1070-1072.

MALONEY. C. (1993) Who should refer to psychotherapy? Referrals to a regional service. Psychiatric Bulletin. 17. 352-354.

MARGISON, F. \& STEWART, A. (1996) General practitioner and psychotherapist referrals to a specialist psychotherapy centre. Psychiatric Bulletin, 20, 418-421.

MoRTON, M. J. \& STAINES. J. (1993) GP use of psychotherapy services. Psychiatric Bulletin. 17. 526-527.

Royal COLLEge OF PSYChIATRISTS (1993) Psychological therapies for adults in the NHS: A joint statement by the British Psychological Society and the Royal College of Psychiatrists.

TASCA, G. A., RusseIL. V. \& BusBy, K. (1994) Characteristics of patients who choose between two types of group psychotherapy. International Joumal of Group Psychotherapy. 44, 499-508.

WoNG, J. L. (1994) Lay theories of psychotherapy and perceptions of therapists: a replication and extension of Furnham and Wardley. Journal of Clinical Psychology. 50. 624-632.

*John R. Mitchell, Senior Registrar, and Chris P. Freeman, Senior Lecturer in Psychiatry. Royal Edinburgh Hospital, Morningside, Edinburgh EH10 5HF

*Correspondence

\title{
Psychotherapy and old age psychiatry
}

\author{
Jane Garner
}

Alms and Methods This report was prepared as the basis for wider consultation within the Old Age Faculty and the College. Some literature and practice is reviewed and practical suggestions made for the future in this area.

Reaults Although older patients are less likely to be refused for psychological intervention attitudes are slowly changing.

Clinical implications The clinical implications of this development include a greater consideration of the unique emotional life of each of our patients and an improved understanding of our reluctance to engage in psychotherapeutic work with older people.

". . near or above the age of fifty the elasticity of the mental processes on which treatment depends is as a rule lacking - old people are no longer educable . . . (Freud, 1905).

Hildebrand (1982) points to a certain irony in these comments as Freud, at the age of 49 , was 